\title{
Patient access to psychiatric records: experience in an in-patient unit
}

\author{
Nick Kosky and Tom Bums
}

\begin{abstract}
Forty of 46 consecuttro admiselons to a poychiatile inpatient unit were encouraged to read their admisetion notes and discuss them with the Junlor doctor. The offer was withheld for two patients with organic impairment. Twenty-elght patients Anctuding 12 on compulsory adiniastons) accopted the offor. The 12 who refused were cheracterteed by overall lower educational aftainment. Diacnoats ratesed only a fow problems, prognoels and maintenance treatment belng the focus of most discuselons. Thore was no ovidence of a defierioration in the quallty of notes or thercpeutic relationships as a consequence of access. Only in one case wos the oxerctes judoed 'harmitu', but 'usetul or escential' in 22. Poselble benefits for both patients and doctor are explored.
\end{abstract}

Changes in national legislation (Access To Medical Records Act, 1989, 1991), the advent of computer stored records (Data Protection Act, 1984), the increase in empowerment of patients, and a shift in the doctor/patient relationship to more partnership in the management of long-term disorders (Tuckett et al, 1985) have all increased pressures for patient access to their own medical notes. In a number of countries (e.g. Sweden, Holland, Denmark) this access is guaranteed unless the doctor insists that it would constitute a substantial risk to the patient's well-being.

Several cliniclans have encouraged their patients to read their records (Baldry et al, 1986; Bird \& Wallf1, 1986). This originated from a wish for better informed patients who can cooperate more fully in the management of their disorders. Resistance to access often focuses on psychiatric patients (Sergeant, 1986) - that their understanding may be limited by the vagueness of psychiatric terminology or by their lack of insight. There is concern that acknowledging the diagnosis may be very depressing for the patient- perhaps reflecting an unduly pessimistic vlew of outcome held by many psychiatrists (Harding et al 1987).

Where patients have been shown their notes and their opinions sought they have generally been posittve about the experience (Miller et al, 1987; Parrot et al, 1988, Baldry et al, 1986) but there is no clear evidence of benefit in treatment compliance or knowledge of the disorders (McFarlane et al, 1980; Miller et al, 1987; Stevens et al, 1977). Psychiatrists are increasingly required to disclose their reports to patients and they must develop skdlls in keeping full and useful notes which can be comfortably shared. We report some consequences for doctors and patients of a trial of open access.

\section{The study}

All consecutive admissions during the course of one year were informed by the reglstrar within two weeks of admission that it was team policy to encourage them to read their own medical notes. An opportunity was offered for them to go through the notes together. The purpose was explained as threefold.

(a) The more you understand about your illness the better prepared you will be to cope with it".

(b) "It will help you understand our thinking about your lliness and management and reassure you that we are being frank".

(c) 'You can correct any important inaccuracies".

Patients who refused or were unsure were offered once more (usually after two to three days or when florid symptoms had receded). 
The meetings were held in prtvate. Access was limited to our own notes of the current admission so that we could be certain of explaining exactly what was meant. Permission for access to other professionals' notes and letters had not been sought. Patients did not have access to their notes without a registrar being present.

For the duration of this study the registrar completed a brief, semi-structured report on the interview. This contained basic demographic data, diagnosis, details of timing and duration of the interview, ease of acceptance of the offer or reasons for refusal. Patients' evaluation of the exercise was rated as "Interesting/pleased to have done it", "neutral, no opinion" or "upsetting/waste of time". Registrars were asked to indicate if the interview was "professionally taxing" or "personally taxing". They were also required to rate its impact on the patient as either "essential", "useful", "neutral", "difficult" or "possibly harmful", or "very difflcult or definitely harmful".

Three reglstrars, two male, one female, were involved consecuttvely in the trial; the same semi-structured format was used by all.

\section{Findings}

Forty-six consecutive admissions were studied over a period of one year. Forty were offered the opportunity to read their notes and six were not. Of these six, four left after brief (one to six days) admissions. A decision to withhold the offer was made for one patient with advanced Pick's disease and one with definite signs of cognitive impairment, being investigated for cerebral SLE.

Twenty-eight (70\%) of those offered accepted the opportunity. The 12 who refused were all voluntary patients. Those who refused had generally lower educational attainments than those who accepted. None had higher education (as opposed to eight out of 28) and only one had ' $A$ ' levels. The remaining 11 had left school with no formal qualifications (as opposed to 12 out of 28). All were literate.

Reasons given for not reading notes were "not interested" in five patients and one each of: "won't help"; "leave it to the doctors"; "worried about what I might find"; "won't understand"; "confuse me"; "upset me" and "not well enough".
Six patients requested access themselves having heard from other patients about it. Twenty accepted readily and two were initially hesitant but decided in favour. The time taken to read the notes ranged from five to 45 minutes with a mean of 22 minutes.

Eighteen of the 28 patients who read their notes were psychotic on admission. Twelve were admitted on either section 2 or 3 of the 1983 Mental Health Act. Diagnoses included 12 of schizophrenia or paranoid psychosis, five of mania, eight of depressive disorders ranging from a delusional patient in need of ECT through to depresstve adjustment reactions and three of personality disorder. Diagnostic issues formed a significant part of the discussion for 19 of the patients. Patients called attention to minor inaccuracies or omissions in most of the notes, although none were considered substantially inaccurate.

Fifteen patients reported that they were pleased they had read their notes. Nine were neutral, having no comment to make about it and four said they found it upsetting. Only one repeated the process although six said they would like to when routinely offered.

Registrars recorded both their own experience of the procedure and their judgement of its value for the patient. Eight of the interviews were considered "professionally taxing" in that patients posed questlons that were difficult to answer with any certainty - (e.g. questions about individual prognosis and long term need for drugs). Six were considered "emotionally taxing" (four of these were also "professionally taxing"). These were predominantly in younger, first episode patients.

Registrars considered the exercise to be "essential" in five patients and "useful" in 17. "Essential" usually denoted interviews in which recovering patients minimised or denied the severity of disturbance and were obliged to confront it in the notes. Four were judged "unremarkable", seeming to have no effect on the patient. The effect on one young woman with personality disorder and selfdamaging behaviour was recorded as "difficult, possibly damaging". None were categorised as "definitely damaging" and information was missing in one case.

\section{Comment}

Instituting the policy of open access to psychiatric notes required extensive 
discussion and negotiation with the other teams sharing the ward as these did not operate the same policy. Considerable disquiet was expressed about it destabilising the normal doctor/patient relationships. The proposal was initially accepted as a timelimited trial but was soon forgotten about as it gave rise to no problems.

The team registrars were also apprehenstve initially and supervision sessions often concentrated on how to phrase admission and progress notes. It was made clear that the content of the notes should not be compromised because of the decision to make them avallable. There is, however, no guarantee that this did not happen. The supervision discussions indicated that registrars took their responsibility seriously and were of considerable teaching value in themselves.

Overall more educated patients welcomed the opportunity, whereas those who were less able and those with longer historles were less interested. They indicated that they had enough to contend with coping with their illness without having to learn about it and expressed relief in "leaving it to the doctor". The greater interest of those with higher educational achievements in open access has been noted before (Anderson \& Jorgensen, 1988).

When diagnosis was discussed, it was evident that most patients had already considered it. Two young schizophrenic patients were visibly distressed by the confirmation of their diagnoses but volunteered that they had feared that it was the case. Patients rarely requested detailed discussions of syndromes or aetlological explanations, but welcomed a clearer understanding of the range of outcome in the disorders. Once aware of this, patients enquired for highly specific predictions of their own likely outcomes. This was often reported as the most taxing part of the interview-both "professionally" and "personally". Reglstrars had learnt prognostic factors for speciflc disorders but found it very difficult to translate these into a discussion of an individual's outcome. The intellectual challenge of this process stood in stark contrast to the ease with which they had previously described prognosis in discharge summarles.

Young manic patients found descriptions in their notes of their behaviour while elated both embarrassing and distressing. Reglstrars found discussing this difficult, and reported that considerable tact and thought were needed to manage it successfully.

Answering the most invariable question "will it happen again ?" was a "personally taxing" issue along with explaining the need for maintenance medication. The doctors found themselves obliged to gtve a realistic estimate of duration for maintenance treatment and vague terms were regularly challenged. "Does a long time mean a year or even more? How many years then? When will you know when to stop or do you mean me to go on for ever ?"

Patlents who read their notes were understandably keen to ensure the accuracy of the record. Corrections made were, from a professional standpoint, minor, but seemed to give patients a sense of 'ownership' of at least part of their treatment, and, surprisingly. there were no difficulties among these patients in accepting the diagnostic process. This may reflect the self-selected nature of the population.

This exercise in openness arose initially out of concerns about the doctor/patient relationship on a ward operating as a modified therapeutic community rather than for health education. We concluded that it provided important training for junior doctors and improved the quality of note-keeping. There was no evidence of reduced detall in the notes. Junior doctors reported that the requirement to phrase their comments in a way that was honest without being offenstve was rapidly learnt and at times helpful in gaining a better understanding of their patients. For example, "she experiences difficulty in meeting her children's needs", prompted consideration of why, and which of her needs had not been met unlike that recorded in a previous admission, "she is a poor mother". The need to consider the course of the illness and explain the details and rationale of management in greater depth increased precision in the use of professional terms and diagnoses.

Whille we doubt that open access alone will have any major effects on treatment compliance, it is a move towards the more equal collaborattve relationship which is increasingly demanded by our patients and their families. The most important findings of this trial are that open access seems to have important training implications and benefits for trainees, that it is less difficult to set up and manage than anticipated, and that it provides an excellent opportunity to discuss with 
patients issues about diagnosis and prognosis. We would recommend further exploration of it with psychiatric patients both inside and outside hospitals.

\section{Acknowledgements}

Our thanks to Richard Corrigal, Katrina Mayo and Rhin Klijnsma for conducting the interviews with the patients.

\section{References}

ANDERson, T. \& JoRGENSEN, G. (1988) Danish experience of statutory right of patients to access hospital records. Lancet, 2, 1428.

Baldry, M., Chral, C., Fisher, B., GuLet, M. \& Huet, V. (1986) Giving patients their own records in general practice: the experiences of patients and staff. Brttish Medical Joumal, 292, 596-598.

BIRD, A. P. \& WAIJ, M. T. I. (1986) Our patients have access to their medical records. Britlsh Medical Joumal, 282. 595-596.

Harding, C. M., ZUBEn, J. \& STRAuss, J. S. (1987) Chronict ty In schizophrenla: fact, partial fact, or artifact? Hospttal and Communtty Psychiatry, 38, 477-486.
Mctapenne, W. J. G., Bowman, R. G. \& Macinnes, M. (1980) Patient access to medical records in a forensic centre - a controlled study. Hospttal and Commentty Psychiatry. 10, 1081-1085.

MUIUR, R. D., MORROW, B., KAYE, M. \& MAIIR, G. J. (1987) Patient access to medical records in a forensic centre - a controlled study. Hospttal \& Communtty Psychiatry, 10. 1081-1085.

Parrott, J., Strathidere, G. \& Brown, P. (1988) Patient access to poychiatric records: the patient's view. Joumal of the Royal Soclety of Medictne, 81, 520-522.

SERGRANT, H. (1986) Should poychiatric patients be granted access to their hospital records? Lancet, 2, 1322-1325.

Stevinus, D. P., Staco, R. \& MACKAy, R. (1977) What happens when hospttalised patients see their own records. Arnals of Internal Medictre, 86, 474-477.

Tucketr, D., Bourton, M. Orson, C. \& Wrunas, A. (1985) Meettings between Experts: an approach to sharting ideas in medical consultations. London \& New York: Tavistock Publications.

Nick Kosky, Senior Registrar; and Tom Burns, Professor, Head of Section and Honorary Consultant, Section of Community Psychiatry, Department of Mental Health Sciences, St George's Hospital Medical School Jenner Wing, Cranmer Terrace, Tooting, London, SWI7 ORE 